\title{
ROLE OF GATED SPECT USING TC 99 SESTAMIBI IN EARLY DETECTION OF SUBCLINICAL HCV RELATED CIRRHOTIC CARDIOMYOPATHY
}

\author{
Marwa Gaber $^{(1)}$, Gamal Amin $^{(1)}$ Moataz Zaki ${ }^{(1)}$, Ahmed Abdelaty ${ }^{(2)}$, Gehan Magdy $^{(2)}$ \\ (1) Department Internal Medicine, Medical Research Institute, Alexandria University, Egypt \\ (2) Department Cardiology department, Alexandria university, Egypt.
}

\begin{abstract}
Background: HCV is one of the health priority in Egypt due to its high prevalence. Cirrhotic cardiomyopathy in manifest stage can affect the patient's prognosis. This study aimed to evaluate the ability of gated SPECT in detection of early $\mathrm{HCV}$ related cirrhotic cardiomyopathy

Methods: We studied forty Child A HCV cirrhotic patients with no other cardiac risk factors by conventional echocardiography and Tc99 sestamibi gated SPECT and twenty normal persons as controls.

Results: the studied group showed blunted response to stress no ischemic changes and normal right ventricular measures.

Conclusions: HCV had an early effect on the heart in the form of chronotropic impairment with stress.
\end{abstract}

Keywords: Gated SPECT, Cirrhotic cardiomyopathy, HCV

\section{INTRODUCTION}

Hepatitis $\mathrm{C}$ is found worldwide. The most affected regions are WHO Eastern Mediterranean and European Regions, with the prevalence of $2.3 \%$ and $1.5 \%$ respectively. ${ }^{(1)}$ It is considered a major health problem in Egypt as it had the highest prevalence rate worldwide. Its prevalence was estimated up to $40 \%$ in some areas. ${ }^{(2)}$ The Egyptian national viral hepatitis treatment program made a successful and effective public health impact. It successfully established a strong infrastructure for controlling hepatitis $\mathrm{C}$ in Egypt ${ }^{(3)}$ In addition to hepatic complications, Two-thirds of patients with HCV infection experienced extrahepatic manifestations. Which vary from common to infrequent. ${ }^{(4)}$

Cirrhotic cardiomyopathy (CCM) is the term used to describe structural and functional cardiac changes that occur in patients with cirrhosis. It includes electrophysiological abnormalities, impairment of systolic and/or diastolic function as well as chronotropic failure, all of which in the absence of known cardiac disease. CCM occur in two stages: a subclinical one, which can be underestimated for a long time, being accidentally discovered by the doctor during a routine exam, and another clinically manifest, the cardiac affection dominating the clinical picture, raising the problem for both the diagnosis as well as treatment ${ }^{(5)}$

A patient complaining of dyspnea, presenting with ascites, without pathological jugular swelling, normal ECG, ECHO with normal ejection fraction, but with elevated B-type natriuretic peptide (BNP) - a condition that may be suggestive of CCM.
Rather than classic presentations of HF, clinical suspicion for early identification, to prevent its evolution to related complications, such as suprarenal insufficiency and hepatorenal syndrome (HRS) is of great value ${ }^{(5)}$

Because CCM is asymptomatic, except during situations of stress, prevalence studies are limited. Heart failure (HF) secondary to $\mathrm{CCM}$ is frequent in patients who undergo liver transplant, in which half the patients presents $\mathrm{HF}$, and up to $21 \%$ die from cardiac causes. ${ }^{(5)}$

Cardiac imaging role in the management of cardiovascular diseases has been increasing nowadays. Noninvasive stress testing, echocardiography provides valuable information regarding the development of clinically important systolic and diastolic dysfunction. Trans-thoracic echocardiography is non-invasive, available at the bedside, and low-cost relative to other imaging modalities. ${ }^{(6)}$ Threedimensional echocardiography (3DE) is becoming more available and increasingly used in clinical practice. Cardiac magnetic resonance (CMR) is a fully automated software allowing fast online measurements and better reproducibility. (7) Nuclear imaging provides a very well-validated test for proper diagnosis of disease pathophysiology, prognosis and guidance towards optimal therapy. ${ }^{(8)}$ It is the preferred technique for risk stratification and prognostication in 
patients in whom prior revascularization has been performed. Pharmacological stress may also be combined with either echocardiography or CMR, where after LV function is evaluated. These methods have similar diagnostic accuracy for viable myocardium. ${ }^{(9}$ )

AIM.

To evaluate the ability of gated SPECT in detection of early HCV related cirrhotic cardiomyopathy

\section{STUDY POPULATION AND METHEDOLOGY:}

Forty patients with Child A HCV related liver cirrhosis diagnosed clinically, laboratory and by abdominal ultrasonography and twenty normal persons as controls. All the patients and the controls were subjected to complete clinical examination and assessment of liver and kidney functions with measurement of cardiac enzymes and tumor marker. Resting ECG, pulse and blood pressure were recorded. Conventional echocardiographic assessment of the right and left ventricles as regard dimensions and systolic and diastolic function. Gated SPECT study using Treadmill stress modality to assess the cardiac parameters in rest and stress states using Tc99 sestamibi.

\section{STATISTICAL ANALYSIS}

Data were fed to the computer and analyzed using IBM SPSS software package version 20.0. (Armonk, NY: IBM Corp) Qualitative data were described using number and percent. Quantitative data were described using range (minimum and maximum), mean, standard deviation and median. Significance of the obtained results was judged at the $5 \%$ level.

\section{The used tests were:}

\section{1 - Chi-square test}

For categorical variables, to compare between different groups

\section{2 - Student t-test}

For normally distributed quantitative variables, to compare between two studied groups

\section{3 - Pearson coefficient}

To correlate between two normally distributed quantitative variables

\section{4 - Mann Whitney test}

For abnormally distributed quantitative variables, to compare between two studied groups

\section{RESULTS:}

This study was held on forty patients (26 males and 14 females) with age ranged between $24-72$ years with a mean of 51years. Laboratory tests were within normal reference ranges in both groups.

Echocardiographic results revealed: first degree diastolic dysfunction was observed in patients while diastolic function was preserved in control group. Assessment of EF (Ejection Fraction) by $\mathrm{M}$-mode was within normal reference ranges in both groups. Right ventricular dimensions, systolic and diastolic functions were within normal reference ranges in both groups. (Table 1)

Gated SPECT studies showed normal resting and stress parameters as regard heart rate, systolic and diastolic blood pressure in both groups. Metabolic Equivalent measurements recording was within average functional capacity for all patients and controls. Stress termination was due to reaching target heart rate in both groups. Blunted chronotropic response to stress was observed in the patients due to the presence of left ventricular dilatation. While normal response to stress was observed in patients group. No filling defects were detected, with no lung uptake, No right ventricular uptake and Calculated ischemic scores were below ischemic ranges in both groups. ( Figure 1-3)

Table (1): The demographic data, laboratory results, echocardiographic findings and gated SPECT results for patients and controls

\begin{tabular}{|c|c|c|c|c|c|c|}
\hline & \multicolumn{2}{|c|}{$\begin{array}{c}\text { HCV } \\
(n=40)\end{array}$} & \multicolumn{2}{|c|}{$\begin{array}{l}\text { Control } \\
(\mathbf{n}=\mathbf{2 0})\end{array}$} & \multirow[t]{2}{*}{ Test of Sig. } & \multirow[t]{2}{*}{$\mathbf{p}$} \\
\hline & No. & $\%$ & No. & $\%$ & & \\
\hline \multicolumn{7}{|l|}{ Sex } \\
\hline Male & 26 & 65.0 & 13 & 65.0 & \multirow{2}{*}{$\chi^{2}=0.0$} & \multirow{2}{*}{1.000} \\
\hline Female & 14 & 35.0 & 7 & 35.0 & & \\
\hline Min. - Max. & \multicolumn{2}{|c|}{$24.0-72.0$} & \multicolumn{2}{|c|}{$24.0-72.0$} & \multirow{3}{*}{$\mathrm{t}=0.127$} & \multirow{3}{*}{0.900} \\
\hline Mean \pm SD & 50.9 & .97 & & .52 & & \\
\hline Median & & & & & & \\
\hline \multicolumn{7}{|l|}{ HB (gm/dl) } \\
\hline Min. - Max. & 16. & & & & \multirow{3}{*}{$\mathrm{t}=1.318$} & \multirow[t]{3}{*}{0.193} \\
\hline Mean \pm SD. & 1.26 & & & & & \\
\hline Median & & & & & & \\
\hline \multicolumn{7}{|l|}{$\operatorname{RBC}\left(10^{6} / \mathrm{mm}^{3}\right)$} \\
\hline Min. - Max. & & & & & \multirow[t]{3}{*}{$\mathrm{t}=0.595$} & \multirow[t]{3}{*}{0.554} \\
\hline Mean \pm SD & 0.6 & & & & & \\
\hline Median & & & & & & \\
\hline \multicolumn{7}{|l|}{$\operatorname{WBC}\left(10^{3} / \mathrm{mm}^{3}\right)$} \\
\hline Min. - Max. & 9.5 & & & & \multirow[t]{3}{*}{$\mathrm{t}=0.5 \quad 71$} & \multirow[t]{3}{*}{0.573} \\
\hline Mean \pm SD & 1.5 & & & & & \\
\hline Median & & & & & & \\
\hline
\end{tabular}




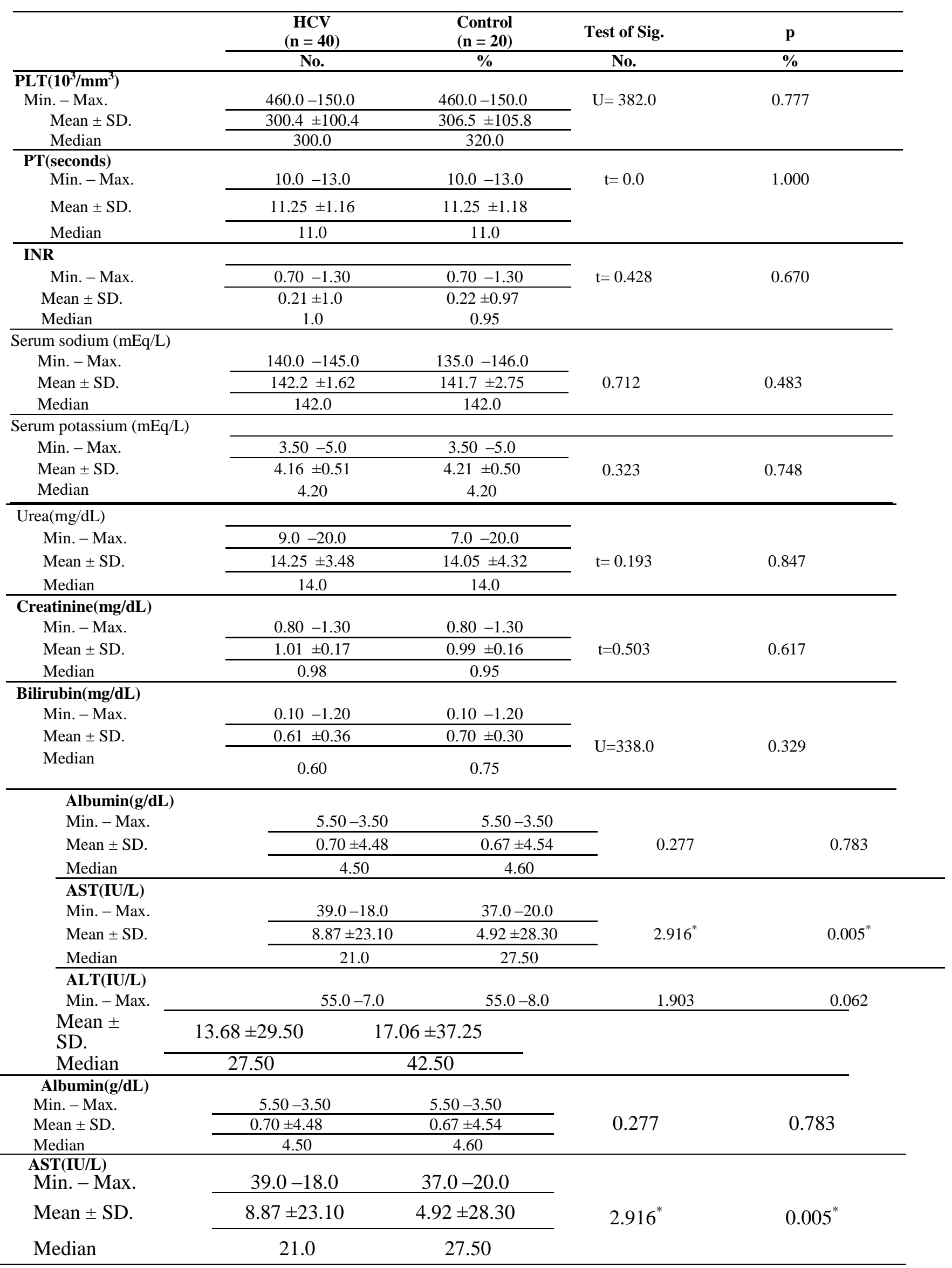




\begin{tabular}{|c|c|c|c|c|}
\hline & $\begin{array}{c}\mathrm{HCV} \\
(\mathrm{n}=40)\end{array}$ & $\begin{array}{l}\text { Control } \\
(\mathbf{n}=\mathbf{2 0})\end{array}$ & Test of Sig. & $\mathbf{p}$ \\
\hline & No. & $\%$ & No. & $\%$ \\
\hline \multicolumn{5}{|l|}{$\overline{\text { ALT(IU/L) }}$} \\
\hline Min. - Max. & $55.0-7.0$ & $55.0-8.0$ & \multirow{3}{*}{1.903} & \multirow{3}{*}{0.062} \\
\hline Mean \pm SD & $13.68 \pm 29.50$ & $17.06 \pm 37.25$ & & \\
\hline Median & 27.50 & 42.50 & & \\
\hline $\begin{array}{l}\boldsymbol{\alpha F P}(\mathbf{n g} / \mathbf{m L}) \\
\text { Min. - Max. }\end{array}$ & $9.0-2.0$ & $9.0-2.0$ & \multirow{3}{*}{0.444} & \multirow{3}{*}{0.659} \\
\hline Mean \pm SD & $2.49 \pm 5.45$ & $2.43 \pm 5.75$ & & \\
\hline Median & 5.0 & 6.0 & & \\
\hline \multicolumn{5}{|l|}{ CK-MB(IU/L) } \\
\hline Min. - Max. & $24.0-5.0$ & $24.0-6.0$ & \multirow{3}{*}{$\begin{array}{c}\mathrm{t}= \\
0.982\end{array}$} & \multirow{3}{*}{0.330} \\
\hline Mean \pm SD & $5.27 \pm 13.85$ & $5.64 \pm 15.30$ & & \\
\hline Median & 14.0 & 15.50 & & \\
\hline \multicolumn{5}{|l|}{ Trop I(ng/ml) } \\
\hline Min. - Max. & $0.39-0.10$ & $0.39-0.10$ & \multirow{3}{*}{$\begin{array}{c}\mathrm{U}= \\
400.0\end{array}$} & \multirow{3}{*}{1.000} \\
\hline Mean \pm SD & $0.11 \pm 0.25$ & $0.11 \pm 0.25$ & & \\
\hline Median & 0.25 & 0.25 & & \\
\hline \multicolumn{5}{|l|}{ Pro BNP (pg/ml) } \\
\hline Min. - Max. & $20.60-125.0$ & $46.0-110.0$ & \multirow{3}{*}{1.675} & \multirow{3}{*}{0.100} \\
\hline Mean \pm SD & $69.65 \pm 27.87$ & $80.05 \pm 19.57$ & & \\
\hline Median & 64.50 & 86.0 & & \\
\hline \multicolumn{5}{|l|}{$\mathrm{E}(\mathrm{cm} / \mathrm{s})$} \\
\hline Min. - Max. & $59.0-88.80$ & $53.0-89.0$ & \multirow{3}{*}{1.353} & \multirow{3}{*}{0.181} \\
\hline Mean \pm SD & $63.75 \pm 16.23$ & $68.20 \pm 9.21$ & & \\
\hline Median & 65.90 & 68.50 & & \\
\hline \multicolumn{5}{|l|}{$\mathbf{A}(\mathbf{c m} / \mathbf{s})$} \\
\hline Min. - Max. & $65.0-94.0$ & $38.0-65.0$ & \multirow{3}{*}{$6.817^{*}$} & \multirow{3}{*}{$<0.001^{*}$} \\
\hline Mean \pm SD & $73.25 \pm 18.51$ & $50.15 \pm 7.64$ & & \\
\hline Median & 74.30 & 48.50 & & \\
\hline E/A & & & & \\
\hline Min. - Max. & $0.54-1.40$ & $1.14-1.84$ & & \\
\hline Mean \pm SD & $0.90 \pm 0.22$ & $1.37 \pm 0.18$ & $8.274^{*}$ & $<0.001^{*}$ \\
\hline Median & 0.84 & 1.30 & & \\
\hline $\mathrm{E} \backslash(\mathrm{cm} / \mathrm{s})$ & & & & \\
\hline Min. - Max. & $5.03-16.0$ & $8.0-16.0$ & & \\
\hline Mean \pm SD & $10.64 \pm 2.98$ & $11.41 \pm 2.34$ & 1.087 & 0.283 \\
\hline Median & 10.0 & 11.40 & & \\
\hline $\mathbf{E} / \mathbf{E} \backslash$ & & & & \\
\hline Min. - Max. & $4.59-15.01$ & $4.17-8.33$ & & \\
\hline Mean \pm SD & $6.47 \pm 2.61$ & $6.18 \pm 1.28$ & 0.585 & 0.561 \\
\hline Median & 6.28 & 6.58 & & \\
\hline EF\% & & & & \\
\hline Min. - Max. & $54.0-75.0$ & $53.0-78.0$ & & \\
\hline Mean \pm SD & $63.38 \pm 6.62$ & $64.05 \pm 6.07$ & 0.382 & 0.704 \\
\hline Median & 62.50 & 63.50 & & \\
\hline TAPSI(mm) & & & & \\
\hline Min. - Max. & $19.0-26.0$ & $19.0-26.0$ & & \\
\hline Mean \pm SD & $22.75 \pm 1.84$ & $22.70 \pm 2.11$ & 0.095 & 0.925 \\
\hline Median & 23.0 & 22.50 & & \\
\hline $\mathrm{S} \mathrm{RV}(\mathrm{cm} / \mathrm{s})$ & & & & \\
\hline Min. - Max. & $12.70-15.0$ & $11.0-18.0$ & & \\
\hline Mean \pm SD & $13.67 \pm 0.64$ & $14.20 \pm 2.09$ & 1.114 & 0.278 \\
\hline Median & 13.73 & 14.0 & & \\
\hline
\end{tabular}




\begin{tabular}{|c|c|c|c|c|}
\hline & $\begin{array}{c}\text { HCV } \\
(n=40) \\
\end{array}$ & $\begin{array}{l}\begin{array}{l}\text { Control } \\
(\mathbf{n}=\mathbf{2 0})\end{array} \\
\end{array}$ & Test of Sig. & $\mathbf{p}$ \\
\hline & No. & $\%$ & No. & $\%$ \\
\hline \multicolumn{5}{|l|}{ E RV $(\mathbf{c m} / \mathbf{s})$} \\
\hline Min. - Max. & $42.0-66.0$ & $49.0-67.0$ & \multirow{3}{*}{1.548} & \multirow{3}{*}{0.127} \\
\hline Mean \pm SD & $55.83 \pm 6.47$ & $58.45 \pm 5.58$ & & \\
\hline Median & 57.0 & 60.0 & & \\
\hline \multicolumn{5}{|l|}{ A RV $(\mathrm{cm} / \mathrm{s})$} \\
\hline Min. - Max. & $32.0-66.0$ & $33.0-55.0$ & \multirow{3}{*}{0.023} & \multirow{3}{*}{0.982} \\
\hline Mean \pm SD & $48.15 \pm 8.68$ & $48.20 \pm 6.13$ & & \\
\hline Median & 48.0 & 50.0 & & \\
\hline \multicolumn{5}{|l|}{ E/A } \\
\hline Min. - Max. & $1.0-1.63$ & $1.0-1.53$ & \multirow{3}{*}{1.260} & \multirow{3}{*}{0.213} \\
\hline Mean \pm SD & $1.18 \pm 0.14$ & $1.23 \pm 0.14$ & & \\
\hline Median & 1.16 & 1.20 & & \\
\hline \multicolumn{5}{|l|}{ Annular RV(mm) } \\
\hline Min. - Max. & $23.0-40.0$ & $25.0-33.0$ & \multirow{3}{*}{1.183} & \multirow{3}{*}{0.242} \\
\hline Mean \pm SD & $31.33 \pm 4.26$ & $30.25 \pm 2.73$ & & \\
\hline Median & 30.0 & 31.0 & & \\
\hline \multicolumn{5}{|l|}{ Mid Cavity RV(mm) } \\
\hline Min. - Max. & $20.0-40.0$ & $27.0-33.0$ & \multirow{3}{*}{0.073} & \multirow{3}{*}{0.942} \\
\hline Mean \pm SD & $5.91 \pm 29.58$ & $1.84 \pm 29.65$ & & \\
\hline Median & 32.0 & 30.0 & & \\
\hline \multicolumn{5}{|l|}{ Long RV(mm) } \\
\hline Min. - Max. & $45.0-79.0$ & $60.0-71.0$ & \multirow{3}{*}{1.496} & \multirow{3}{*}{0.140} \\
\hline Mean \pm SD & $64.58 \pm 7.39$ & $66.7 \pm 3.61$ & & \\
\hline Median & 65.0 & 67.50 & & \\
\hline \multicolumn{5}{|l|}{ Rest EF by SPECT } \\
\hline Min. - Max. & $60.0-78.0$ & $55.0-75.0$ & \multirow{3}{*}{1.836} & \multirow{3}{*}{0.071} \\
\hline Mean \pm SD & $67.38 \pm 5.29$ & $64.6 \pm 5.95$ & & \\
\hline Median & 67.50 & 65.0 & & \\
\hline \multicolumn{5}{|l|}{ Stress EF by SPECT } \\
\hline Min. - Max. & $55.0-77.0$ & $65.0-90.0$ & \multirow{3}{*}{$3.072^{*}$} & \multirow{3}{*}{$0.005^{*}$} \\
\hline Mean \pm SD & $68.25 \pm 5.90$ & $74.9 \pm 8.8$ & & \\
\hline Median & 68.0 & 71.50 & & \\
\hline
\end{tabular}

\section{t: Student t-test}

$\mathrm{p}$ : $\mathrm{p}$ value for comparing between the two studied groups

*: statistically significant at $\mathrm{p} \leq 0.05$

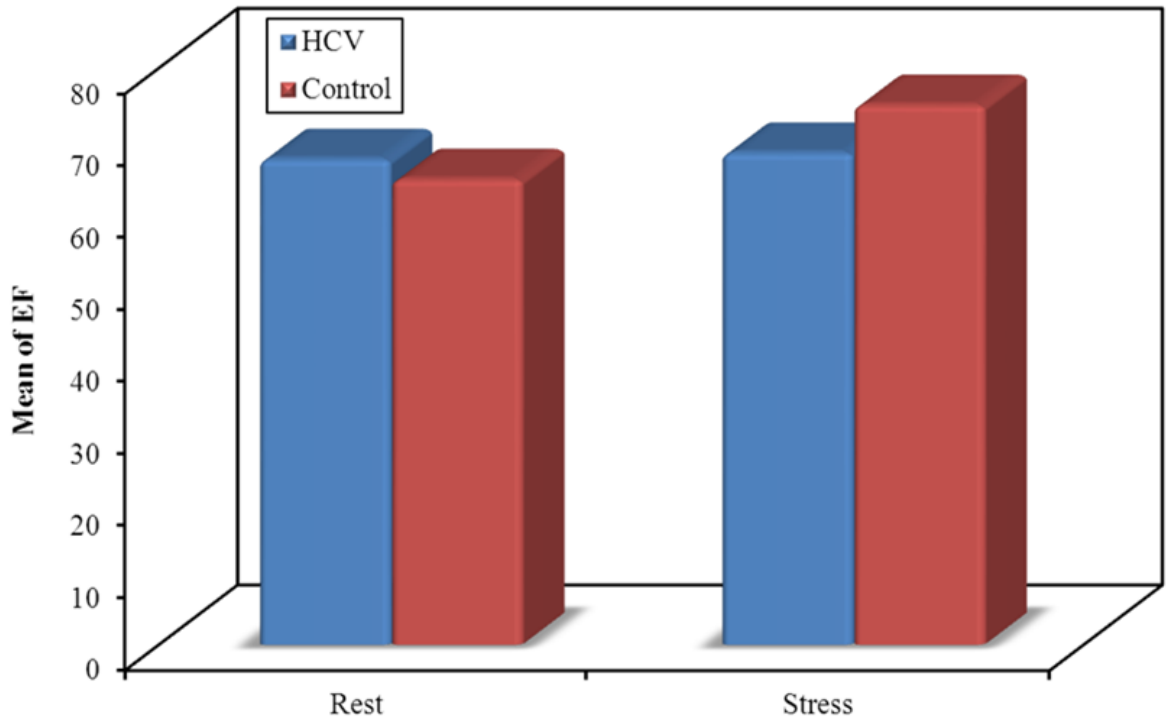

Figure (1): Estimated EF during rest and stress by Gated SPECT 


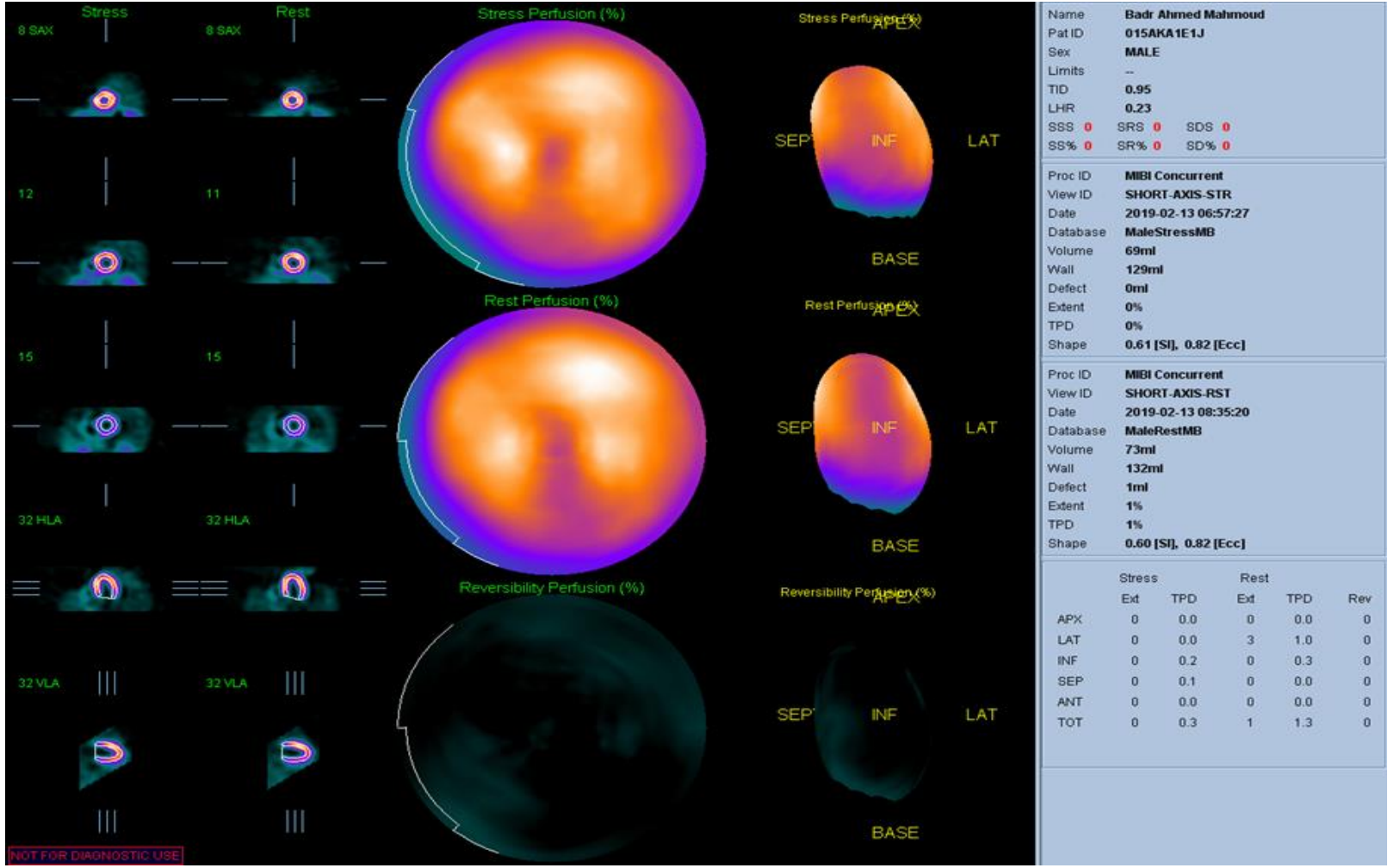

Figure (2): Gated SPECT study of one of our patients

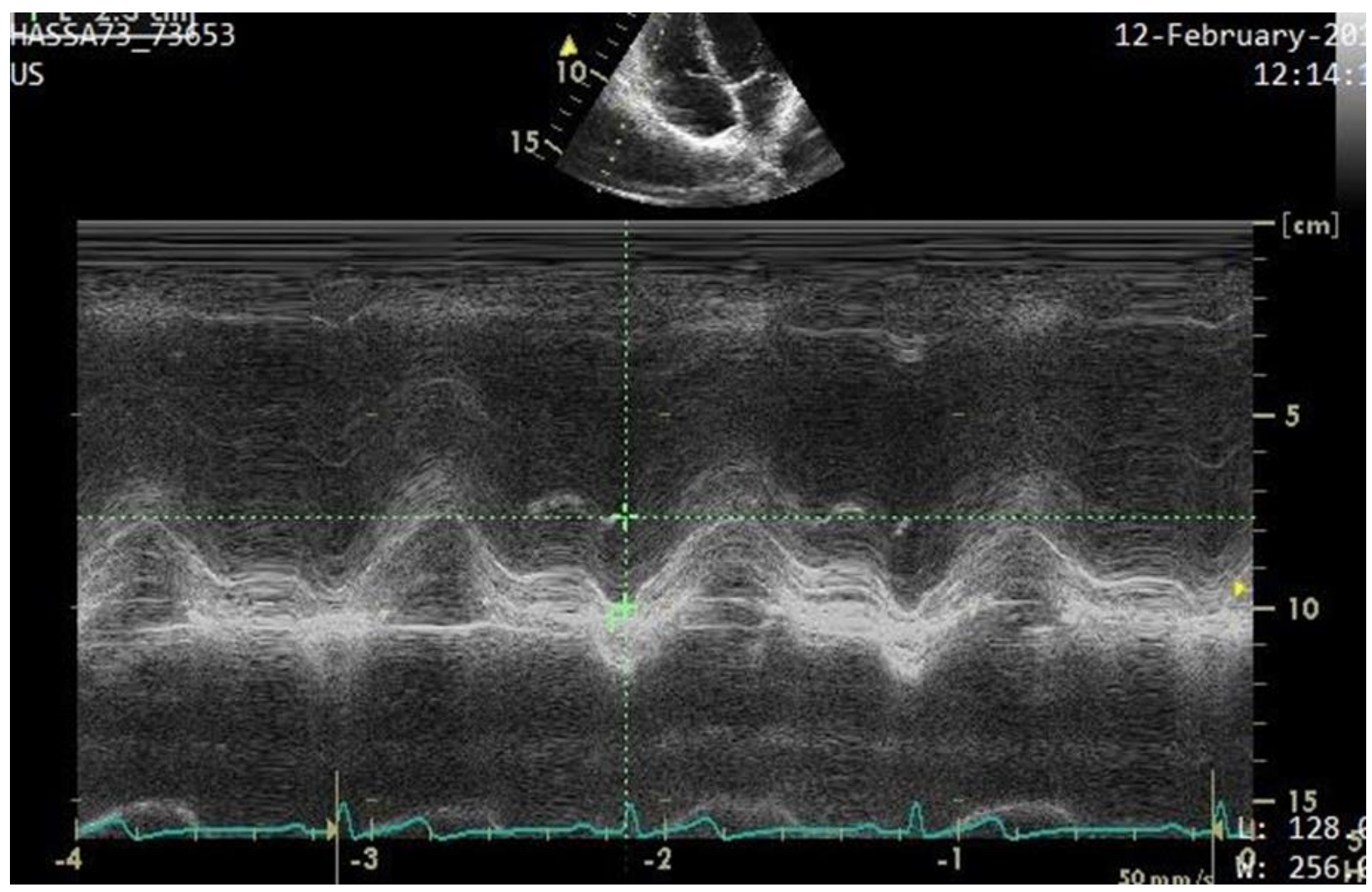

Figure 3: Assessment of right ventricular function by TAPSI 


\section{DISCUSSION:}

Cirrhotic cardiomyopathy (CCM) is characterized by an impaired contractile response to stress, diastolic dysfunction and the presence of electrophysiological abnormalities, and it may be diagnosed at rest in some patients or demasked by physiological or pharmacological stress. CCM is associated with an impaired survival. ${ }^{(10)}$ In this study, we included $40 \mathrm{HCV}$ patients diagnosed by PCR and a 20 normal persons as a control group. The patients were collected from the newly discovered cases in a national campaign held in Egypt in 2019 for detection and treatment of $\mathrm{HCV}$ patients. The patients and the controls were subjected to laboratory testing and abdominal ultrasonography to ensure their compatibility to the study criteria.

In our study there were no significant differences between patients' group and control group as regard $\mathrm{E}$ and $\mathrm{A}$ waves values, but in E/A ratio the patients group was lower than control group which indicates grade I diastolic dysfunction in patients group. The measurements of $E^{\prime}$ did not differ significantly between both groups which was reflected on $\mathrm{E} / \mathrm{E}^{\backslash}$ ratio in both groups did not differ significantly. In Sampaio et al study. ${ }^{(6)}$ assessment of diastolic functions were done by $\mathrm{E}, \mathrm{A}, \mathrm{E} / \mathrm{A}$ ratio, deceleration time, $E^{\prime}$ and $E / E^{\prime}$ ratio. The results in this study showed significant differences in all the parameters. In our study the ejection fraction assessed by echocardiography was within normal reference ranges in patients and control groups with no significant differences between both groups. In Sampaio et al. ${ }^{(6)}$ The ejection fraction measurements were within normal reference ranges in both patients and control groups with no significant difference between both groups as in our study. Assessment of systolic functions using TAPSI revealing perseveration of systolic functions of the right ventricle in patients group. Measurement of right ventricular dimensions (annular, mid cavity and longitudinal) revealed normal reference ranges. In Sampaio et $a l .{ }^{(6)}$ Right ventricular function evaluated by tricuspid annulus plane systolic excursion (TAPSE) was not different between patients and controls as in our study.

In our study, the gated SPECT studies were done, all were subjected to treadmill stress till reaching target heart rate. Resting heart rate, systolic blood pressure and diastolic blood pressure were within normal reference ranges. The cause of test terminations was reaching target heart rate and no other causes detected. Metabolic equivalents measurement showed good functional capacity. Peak heart rate and systolic and diastolic blood pressure measurements were with normal reference ranges. The ejection fraction calculation by gated SPECT in resting images showed normal values. While ejection fraction calculation at stress images showed lower values. Left ventricular dilatation with stress was observed in patients. Calculated SSS, SRS and SDS were below ischemic ranges. No signs of right ventricular ischemia or lung uptake were observed. In Wong et al. ${ }^{(11)} \mathrm{EF}$ and cardiac volumes were analyzed. The patient was seated upright on an automated exercise cycle, the study showed reduced cardiac response to exercise. When increase in EF with exercise in cirrhotic was compared with controls, this was significantly reduced as in our study. Consequently, both the absolute and percentage increases in cardiac output in cirrhotic patients were also significantly decreased compared with controls.

\section{CONCLUSIONS:}

1. Hepatitis $C$ virus had a subclinical effect on the heart.

2. Gated SPECT is a good modality in detection of subclinical cirrhotic cardiomyopathy as it showed the chronotropic abnormalities.

3. Subclinical cirrhotic cardiomyopathy does not affect the right side of the heart.

4. Conventional echocardiography is not the modality of choice in subclinical cirrhotic cardiomyopathy detection.

\section{REFERENCES:}

1. WHO. Hepatitis C report 2018]

2. Elgharably A, Gomaa AI, Crossey MM, Norsworthy PJ, Waked I, Taylor-Robinson SD. Hepatitis C in Egypt-past, present, and future. International journal of general medicine. 2017;10:1

3. El- Akel W, El- Sayed M, El Kassas M, El- Serafy M, Khairy M, Elsaeed K, et al. National treatment programme of hepatitis C in Egypt: Hepatitis C virus model of care. Journal of viral hepatitis. 2017;24(4):262-7.

4. Ilyas SZ, Tabassum R, Hamed H, Rehman SU, Qadri I. Hepatitis $\mathrm{C}$ virus-associated extrahepatic manifestations in lung and heart and antiviral therapy-related cardiopulmonary toxicity. Viral immunology. 2017;30(9):633-41.

5. Petta S. Hepatitis $C$ virus and cardiovascular: A review. Journal of advanced research. 2017;8(2):161-8.

6. Sampaio F, Pimenta J, Bettencourt N, Fontes- Carvalho R, Silva AP, Valente J, et al. Systolic and diastolic dysfunction in cirrhosis: a tissue- Doppler and speckle tracking echocardiography study. Liver International. 2013; 33(8): 1158-65.

7. Sampaio F, Pimenta J. Left ventricular function assessment in cirrhosis: Current methods and future directions. World journal of gastroenterology. 2016;22(1):112.

8. Holly TA, Abbott B, Al-Mallah M, Calnon D, Cohen M, DiFilippo $\mathrm{F}$, et al. ASNC imaging guidelines for nuclear cardiology procedures. J Nucl Cardiol. 2010;17:941-73.

9. Chong A, MacLaren G, Chen R, Connelly KA. Perioperative applications of deformation (myocardial strain) imaging with speckle-tracking echocardiography. Journal of cardiothoracic and vascular anesthesia. 2014;28(1):128-40.

10. Wiese S, Hove JD, Mo S, Mygind ND, Tønnesen J, Petersen CL, et al. Cardiac dysfunction in cirrhosis: a 2- 
year longitudinal follow-up study using advanced cardiac imaging. American Journal of Physiology-Gastrointestinal and Liver Physiology. 2019.
11. Wong F, Girgrah N, Graba J, Allidina Y, Liu P, Blendis L. The cardiac response to exercise in cirrhosis. Gut. 2001;49(2):268-75. 